\title{
EXISTENCE AND EFFICIENCY OF STATIONARY STATES IN A RENEWABLE RESOURCE BASED OLG MODEL WITH DIFFERENT HARVEST COSTS
}

\author{
Karl FARMER* \\ University of Graz, Graz, Austria \\ Birgit BEDNAR-FRIEDL \\ University of Graz, Graz, Austria
}

\begin{abstract}
In a renewable resource based overlapping generations (OLG) model without harvest costs, a complex combination of the time discount factor, the resource production share, and the natural regeneration rate ensure the existence of a stationary market equilibrium and its intergenerational efficiency when the own rate of return on natural capital is positive. This paper investigates to what extent previous findings carry over to an OLG economy with two types of unit harvest costs (constant, inverse stock dependent) arising from the competition for labor between resource harvesting and resource processing. In contrast to the model without harvest cost, we show why large unit harvest costs, surprisingly, do not require a complex combination of basic parameters for the existence of a stationary state, and that in the model with stock dependent costs intergenerational efficiency might occur even when the own rate of return on natural capital is negative.
\end{abstract}

JEL classification: C62; D90; Q20

Keywords: Renewable resources, harvest costs, overlapping generations, existence, intergenerational efficiency

\section{Introduction}

There is no such thing as free lunch - or in the context of natural resources, harvesting involves effort which translates into costs in terms of time and/or money. For any renewable resource, harvest costs can be constant, depend on the harvest

* Corresponding author. Address: Institute of Economics, University of Graz, Universitätsstraße 15, A-8010 Graz, Austria, phone: +43 316 380-7113, E-mail: karl.farmer@uni-graz.at 
volume or on the resource stock (Bjørndal et al., 1993; Grafton et al., 2007). Constant harvest costs characterize a resource which is difficult to access but once access is achieved harvesting leads to no additional costs. ${ }^{1}$ In real world situations, constant harvest costs are hardly found for renewable resources, but it is a common (implicit) modeling assumption because it seems to be merely a generalization of the case without harvest cost (Smith, 1968). Harvest costs that depend on the harvest volume are typical for many renewable resources which are available in abundance, such as aquaculture or wood (Smith,1968; Heaps and Neher, 1979). Finally, harvesting effort and hence costs can also depend on the resource stock following the general wisdom 'the larger the stock, the easier to catch.' (Clark and Munro, 1975)

While the importance of harvest costs is fully acknowledged in partial equilibrium models of resource dynamics (Clark and Munro, 1975; Levhari et al., 1981; Olson and Roy, 1996), harvest costs of any types are hardly found in dynamic general equilibrium models (exemptions being: Krutilla and Reuveny, 2004; Elíasson and Turnosvsky, 2004; Bednar-Friedl and Farmer, 2013). ${ }^{2}$ In contrast to partial equilibrium resource dynamic models, in dynamic general equilibrium models with interdependent factor and product markets as well as asset markets the existence of stationary (steady) states cannot be taken for granted, in particular in dynamic general equilibrium models of the overlapping generations (OLG) type. ${ }^{3}$ In fact, in a renewable resource based OLG model without harvest costs a complex combination of the time discount factor of households, the resource production share of firms, and the natural regeneration rate is needed to ensure the existence of stationary market equilibrium (Mourmouras, 1991; Farmer, 2000; Koskela et al., 2002). Moreover, in OLG models without harvest costs only those stationary market equilibrium solutions are intergenerationally efficient where the own rate of return on natural capital is positive (Koskela et al., 2002).

The goal of this paper is therefore to investigate to what extent the conditions for the existence and intergenerational efficiency of stationary market equilibria in the model without harvest cost carry over to OLG models with harvest costs. In this OLG economy, harvest costs arise from the competition for labor between resource harvesting and resource processing, and unit harvest costs can either be constant or depend inversely on the resource stock. Based on partial equilibrium resource dynamics insight, one might presume that the magnitude of the harvest costs parameter is instrumental for the question whether the rather demanding existence

1 Yet, fixed costs can occur in addition to operating costs (see e.g. Smith, 1968). An example for fixed costs are investment costs for harvesting equipment, such as for the fishing fleet in fisheries or harvesting machines and access roads in forestry.

2 Although probably to the surprise of the general economic reader, there is to the best of our knowledge not any recent literature on different types of harvest costs in renewable resource based OLG models.

3 The advantage of an OLG model as compared to Ramsey-type growth models with infinitely lived agents (ILA) or a benevolent social planner is that the OLG framework is better capable to capture the finite lifetime of households versus the infinite lifetime of natural resources and the consequences for resource harvest and conservation when the resource stock serves as store of value across adjacent generations (e.g. Howarth and Norgaard, 1990; Mourmouras, 1991; Olson and Knapp, 1997; Krautkraemer and Batina, 1999; Koskela et al., 2002; Valente, 2008; Bréchet and Lamprecht, 2011; Bednar-Friedl and Farmer, 2013). 
conditions obtained for the no-harvest cost case hold also under harvest costs. In this paper we therefore analyze whether the existence conditions, which are necessary for the no-harvest costs case, are required also for the case with harvest costs, how the magnitude of the harvest cost parameter might change this conditions, and whether there is a difference between constant and inversely stock dependent unit harvest costs.

It is well known for OLG models in general that a stationary-state market equilibrium can be intergenerationally inefficient because of the double infinity of goods and agents (Shell, 1971). Redistribution of savings and hence consumption between the young and old generation could lead to a Pareto improvement (de la Croix and Michel, 2002). In case of a renewable resource based economy, an inefficient stationary-state market equilibrium corresponds to a case where the opportunity costs of holding the resource stock are negative - a situation which would imply a negative own rate of return on assets (Koskela et al., 2002). Assuming constant or inversely stock dependent harvest costs, we therefore investigate the range of the harvest costs parameter on which intergenerational efficiency respectively inefficiency occurs. Since to the best of our knowledge intergenerational efficiency in an OLG economy with harvest costs is not investigated at all in the literature, in the second part of the paper we derive the necessary conditions for a stationary intergenerationally efficient allocation under both types of harvest costs and then explore under which conditions stationary market equilibrium allocations are intergenerationally efficient.

This paper demonstrates that the incorporation of harvest costs, and in particular whether harvest costs depend only on the harvest level or also inversely on the resource stock, has profound implications for the existence and intergenerational efficiency of stationary state solutions in the OLG framework. ${ }^{4}$ Regarding existence, we find that the existence conditions, which are necessary for the no-harvest costs case, are required also for the case with harvest costs, but only when unit harvest costs are comparatively small. When unit harvest costs are however large, the restrictions on basic model parameters (besides the harvest cost parameter) are no longer required. Since this result is at first sight surprising, we will also show why this is the case. Moreover, we find that only a subset of all biologically feasible resource stocks is economically feasible in the model with harvest costs while no such restriction applies in the model without harvest costs. In order to ensure positive (economically feasible) resource stock prices in general equilibrium, the harvest price has to be larger than the marginal harvest costs. We show on which subsets of biologically feasible resource stocks the resource stock price is indeed positive.

Regarding intergenerational efficiency, the main second insight of this paper is that not only the magnitude of the harvest cost parameter, but also the type of harvest costs, matters for the intergenerational efficiency of the stationary state. While under constant unit harvest costs stationary market equilibrium allocations are intergenerationally efficient for a positive own rate of return on the resource stock (as under no harvest), this is not the case for inversely stock dependent unit harvest costs. In particular, it turns out that the stationary market equilibrium can be intergenerationally efficient even when the own rate of return on natural capital is negative.

4 Comparative dynamics subject to economic and biological shocks is beyond the scope of the present paper. For the analysis of the steady state effects of those shocks in a comparable deterministic OLG model see Bednar-Friedl and Farmer (2013) and in a stochastic environment Kennedy and Barbier (2015). 
There are thus two main contributions of this paper to the literature on renewable resource based OLG models still succinctly represented by Koskela et al.'s (2002) canonical resource dynamical general equilibrium model without harvest costs. First, in addition to and as the former authors we perform a thorough mathematical analysis of the existence, uniqueness and dynamical stability of stationary market equilibria both for constant and inverse stock-dependent unit harvest costs albeit for the special case of loglinear utility and Cobb-Douglas production functions. Second, also in addition to Koskela et al.'s (2002) intergenerational efficiency analysis without harvest costs we compare extensively the stationary market equilibrium solution under both harvest costs types to the corresponding intergenerational efficiency planer solutions.

The remainder of the paper is structured as follows. Section 2 provides the description of the model, including a characterization of the different types of harvest costs. Section 3 derives the conditions for the existence, uniqueness and asymptotic stability of a nontrivial stationary state for each type of harvest costs. The intergenerational efficiency of these solutions is analyzed and compared in section 4. Section 5 discusses our results and concludes.

\section{Model description}

This chapter provides a concise description of the general modeling framework which consists of a standard (Diamond, 1965)-type OLG model with a renewable resource stock with concave regeneration and different types of harvest cost function. The basic model without harvest costs is closely related to the special case of log-linear utility and Cobb-Douglas technology in Koskela et al. (2002). Into this model we introduce two types of resource harvest cost by assuming that harvesting competes with resource processing for labor and that the costs of harvesting are borne by the younger generation as the resource owner (as in Bednar-Friedl and Farmer, 2013). The renewable resource is used as input in resource processing.

\subsection{Household and firm optimization}

To be able to analytically elaborate the consequences of different types of harvest cost, we assume log-linear utility and Cobb-Douglas technology and logistic resource growth. ${ }^{5}$ Moreover, we assume that the renewable resource is the only store of value. ${ }^{6}$

The representative consumer's intertemporal utility depends on consumption during the working period, $C_{t}^{1}$, and consumption during the retirement period, $C_{t+1}^{2}:{ }^{7}$

5 As shown by Lloyd-Braga et al. (2007), more general utility functions generate multiple steady state solutions which we want to avoid in order to be able to focus on the existence and intergenerational efficiency implications of different types of harvest cost.

6 In contrast to a model with a renewable resource stock and physical capital as in BednarFriedl and Farmer (2013), abstracting from physical capital keeps the analysis more tractable, i.e. the analysis of existence, stability and efficiency can be performed without having to resort to numerical analysis. At the same time, the general insights from this simpler model are quite similar to the case with two stocks.

7 Because population is normalized to one, $C_{t}^{1}$ and $C_{t+1}^{2}$ are either per-capita consumption or aggregate consumption in the working and retirement period, respectively. 
The representative young household's preferences are represented by a loglinear intertemporal utility function:

$$
u=u\left(C_{t}^{1}, C_{t+1}^{2}\right)=\ln C_{t}^{1}+\beta \ln C_{t+1}^{2},
$$

with $0<\beta<1$ denoting the old-age utility discount factor.

When young the household splits her working time (normalized to one) between employment in the production sector and resource harvesting effort $h$. The young household thus gains wage income and revenues from selling the resource harvest $X_{t} \cdot{ }^{8}$ These revenues are spent on consumption $C_{t}^{1}$ and acquisition of the renewable resource stock $R_{t}^{d}$ for transferring income to their retirement period. The resource stock $R_{t}^{d}$ is bought from the older household in a competitive market at the beginning of the period. ${ }^{9}$

The budget constraint in the working period is thus:

$$
p_{t} R_{t}^{d}+C_{t}^{1}=w_{t}\left(1-h\left(R_{t}^{d}\right) X_{t}\right)+q_{t} X_{t},
$$

where $w_{t}$ denotes real wage, $q_{t}$ the price of resource harvest, $p_{t}$ the price of the resource stock demanded, and the consumption good in period $t$ serves as the numeraire.

The old household gains revenues from selling the resource stock in the retirement period, which is spent on consumption $C_{t+1}^{2}$ :

$$
C_{t+1}^{2}=p_{t+1} R_{t+1} \text {. }
$$

The resource stock evolves according to:

$$
R_{t+1}=R_{t}^{d}+g\left(R_{t}^{d}\right)-X_{t},
$$

where $g\left(R_{t}^{d}\right)$ denotes the concave resource regeneration function which is specified as logistic:10 $g\left(R_{t}^{d}\right)=r\left[R_{t}^{d}-\left(R_{t}^{d}\right)^{2} / R_{\max }\right]$, where $r>0$ denotes the regeneration rate and $R_{\max }$ the carrying capacity.

8 This assumption is very similar to the one used by Elíasson and Turnovsky (2004) in an endogenous growth model of the ILA type in which they assume that labor is allocated between a resource extraction and a processing sector.

9 As a consequence of exclusive private property rights (as for e.g. a fish pond or a fishing ground), the younger household acquires the resource stock from the older household in the competitive resource stock market at the beginning of the period and can also appropriate the revenues from resource harvest in the current market period. In contrast to this beginning-of-period market equilibrium notion, (Koskela et al., 2002) use the endof-period asset market equilibrium concept.

10 This is the standard assumption in OLG models with a renewable resource (see e.g. Krautkraemer and Batina, 1999; Farmer, 2000; Koskela et al. 2002; Bednar-Friedl and Farmer, 2013). 
Finally, the unit harvest cost function $h\left(R_{t}^{d}\right)$ is assumed to have the following properties: $h^{\prime}\left(R_{t}^{d}\right) \leq 0$. Throughout the paper, three different versions of unit harvest cost functions will be used representing the idea that resource harvest requires labor (or effort) as input (Krutilla and Reuveny, 2004; Elíasson and Turnovsky, 2004).

In case of constant unit harvest cost, we have: ${ }^{11}$

$$
h\left(R_{t}^{d}\right)=\lambda, \lambda>0 .
$$

Alternatively, we will assume that unit harvest costs are inversely related to the resource stock: ${ }^{12}$

$$
h\left(R_{t}^{d}\right)=\frac{\lambda}{R_{t}^{d}},
$$

yielding a total cost function which is linear in the harvest volume and inversely stock dependent: $h\left(R_{t}^{d}\right) X_{t}=\left(\lambda X_{t}\right) / R_{t}^{d}$. As a benchmark to which we compare the two types of harvest costs, we will also analyze the case of no harvest costs: $h\left(R_{t}^{d}\right)=0$.

The representative household thus chooses $C_{t}^{1}, C_{t+1}^{2}, R_{t}^{d}$, and $X_{t}$ to maximize (1) taking account of (2)-(6). This yields the following first order condition for intertemporal consumption decisions:

$$
\frac{C_{t+1}^{2}}{\beta C_{t}^{1}}=\frac{\left[1+g^{\prime}\left(R_{t}^{d}\right)\right] p_{t+1}}{p_{t}+w_{t} h^{\prime}\left(R_{t}^{d}\right) X_{t}} .
$$

Eq. (7) thus requires that the intertemporal marginal rate of substitution between consumption when young and consumption when old equals the net return factor on the resource stock.

The second condition equates the price of the resource stock to the net return on resource harvest:

$$
p_{t}=\left[q_{t}-w_{t} h\left(R_{t}^{d}\right)\right]\left[1+g^{\prime}\left(R_{t}^{d}\right)\right]-w_{t} h^{\prime}\left(R_{t}^{d}\right) X_{t} .
$$

For the case without harvest cost $\left(h\left(R_{t}^{d}\right)=0\right)$,(8) simplifies to $p_{t}=q_{t}\left[1+g^{\prime}\left(R_{t}^{d}\right)\right]$, i.e. the resource stock price has to be equal to the harvest price taking account of resource regeneration in the respective period. With linear harvest costs, the revenue from selling the resource harvest is reduced by the costs involved in harvesting $\left(w_{t} h\left(R_{t}^{d}\right)\right)$. If harvesting effort depends additionally on the resource

11 In line with basic economic reasoning, we could also assume that total harvest costs are not linear but quadratic in the harvest level. While the analysis turns out much more complicated, the qualitative results are similar as in the case of linear harvest cost.

12 Multiplying the right hand side of (6) by $X_{t}$ gives total harvest costs. Solving this expression for $X_{t}$ yields the well-known Schaefer (1954) harvest function, a functional specification popular in mostly (partial) equilibrium fishery models (Clark, 1990; Conrad, 1999; Brown, 2000; Maroto et al., 2012). 
stock, then the revenues on harvesting are increased by keeping an additional unit unharvested (because of $h^{\prime}\left(R_{t}^{d}\right)<0$ ).

The firm is assumed to behave competitively and to maximize profits given output and input prices. The output of resource processing is described by a constant-returns-to-scale Cobb-Douglas production function with labor $N_{t}^{d}$ and resource harvest $X_{t}$ as inputs: $Y_{t}=\left(X_{t}^{d}\right)^{\alpha}\left(N_{t}^{d}\right)^{1-\alpha}$. The firm's first order conditions read as follows:

$$
q_{t} X_{t}^{d}=\alpha Y_{t}, w_{t} N_{t}^{d}=(1-\alpha) Y_{t} .
$$

All markets are assumed to clear every period, i.e. the markets for the resource stock $\left(R_{t}^{d}=R_{t}, \forall t\right)$, for resource harvest $\left(X_{t}^{d}=X_{t}, \forall t\right)$, and for labor $\left(N_{t}^{d}=1-h\left(R_{t}\right) X_{t}, \forall t\right)$. Finally, market clearing for the output of the resource processing sector coincides with Walras' Law and is therefore redundant:

$$
\left(X_{t}\right)^{\alpha}\left[1-h\left(R_{t}\right) X_{t}\right]^{(1-\alpha)}=C_{t}^{1}+C_{t}^{2},
$$

where

$$
\begin{aligned}
& C_{t}^{1}=\gamma\left\{w_{t}\left[1-h\left(R_{t}\right)\left(\Phi\left(R_{t}\right) R_{t}+X_{t}\right)\right]+q_{t} \Phi\left(R_{t}\right) R_{t}\right\}, \\
& C_{t}^{2}=\left[1+g^{\prime}\left(R_{t}\right)\right]\left[q_{t}-h\left(R_{t}\right) X_{t}\right] R_{t}+w_{t} h\left(R_{t}\right) X_{t},
\end{aligned}
$$

and where $\gamma \equiv 1 /(1+\beta)$, and $\Phi\left(R_{t}\right) \equiv g\left(R_{t}\right) / R_{t}-g^{\prime}\left(R_{t}\right)$ being the resource rent.

\subsection{The stationary state market equilibrium}

As in Koskela et al.'s (2002) model with log-linear utility function and CobbDouglas technology, the intertemporal equilibrium dynamics can be reduced to a one-dimensional system in $R_{t}$. By using household's and firm's first order conditions (1)-(6) in the goods market clearing condition (10), setting $X_{t+1}=X_{t}=X, \forall t$ and $R_{t+1}=R_{t}=R, \forall t$, and acknowledging that according to (4) $X=g(R)$ the following stationary state relationship is obtained:

$$
\Psi(R)=\frac{g(R)\left\{[1-\gamma(1-\alpha)] R-\left[h(R) R-(1-\gamma)(1-\alpha) h^{\prime}(R) R^{2}\right] g(R)\right\}}{R[a-h(R) g(R)]},
$$

where $\Psi(R) \equiv\left\{\gamma \Phi(R)+\left[1+g^{\prime}(R)\right]\right\} R$. In the following, we will denote the left hand side of (13), in case of no harvest cost, by $\operatorname{LHSO}(R)$ and the right hand side by $\operatorname{RHSO}(R)$ (see Figs. 1-2). For linear harvest cost, they will be denoted by $\operatorname{LHSL}(R)$ and $\operatorname{RHSL}(R)$ (see Figs. 3-4) and for inversely stock dependent by $\operatorname{LHSR}(R)$ and $\operatorname{RHSR}(R)$ (see Figs. 5-6). 
Inspecting the denominator of (13) reveals that this function can exhibit a pole when $[\alpha-h(R) g(R)]=0$. Evidently this cannot occur in the model version without harvest cost because then $h(R)=0$. For the model with linear harvest cost, two poles can emerge (see Fig. 4). In contrast, in the model with inversely stock dependent harvest cost, only one pole emerges (see Fig. 6). As a consequence of the emergence of poles, Proposition 1 thus states that without harvest costs all biologically feasible resource stock values $\left(0<R<R_{\max }\right)$ are also economically feasible while with constant or inversely stock dependent harvest cost only a subset of all biologically feasible resource stocks is also economically feasible.

\section{Proposition 1 (Economic feasibility)}

Without harvest cost, all resource stocks $R \in\left(0, R_{\max }\right)$ are economically feasible. With linear harvest costs, for $\lambda r R_{\max }-4 \alpha<0$ all resource stocks $R \in\left(0, R_{\max }\right)$ are economically feasible while for $\lambda r R_{\max }-4 \alpha>0$ all resource stocks $R \in\left(0, \hat{R}_{1}\right) \cup\left(\hat{R}_{2}, R_{\max }\right)$ are economically feasible, and for $\lambda r R_{\max }-4 \alpha=0$ all resource stocks $R \in\left(\hat{R}_{2}, R_{\max }\right)$ are economically feasible. With inversely stock dependent harvest cost, for $\lambda \leq \alpha / r$ all resource stocks $R \in\left(0, R_{\max }\right)$ are economically feasible while for $\lambda>\alpha / r$ all resource stocks $R \in\left(\hat{R}_{2}, R_{\max }\right)$ are economically feasible.

Proof 1: See Appendix A.1.

According to Proposition 1, constant unit harvest costs with a sufficiently large harvest cost parameter lead to two ranges of economically feasible resource stocks: to the left of the smaller pole $\hat{R}_{1}$ and to the right of the larger pole $\hat{R}_{2}$. Between these poles the resource stock price, which equals the difference between the price of the harvest and the marginal harvest cost, becomes negative precluding an economically feasible stationary state solution (see gray shaded area in Fig. 4). ${ }^{13}$ The reason for the economic infeasibility of intermediate values of the resource stock is that, due to logistic regeneration, the harvest volumes are highest for intermediate values of the resource stock and that therefore associated total harvesting effort, $\lambda X$, exceeds the production share of harvest input $\alpha$.

In contrast, with stock dependent harvest cost, and a sufficiently large harvest cost parameter, economically feasible resource stock values are only found to the right of the only pole $\hat{R}_{2}$ (the gray shaded area in Fig. 6 indicates again the range of economic infeasibility). Thus, while for linear harvest cost both small and large resource stocks are feasible (but not intermediate sized ones), only large resource stock values are feasible with inversely stock dependent harvest costs. This finding can be attributed to marginal harvest costs: because they are decreasing in the latter

13 To see that, we evaluate (8): $p=[q-w h(R)]\left[1+g^{\prime}(R)\right]-w h^{\prime}(R) g(R)$. A sufficient condition for $p>0$ is that $q-w h(R)>0$. After substituting for the firm's first order conditions, this condition is equivalent to $\alpha[1-h(R) X]>(1-\alpha) h(R) X \Leftrightarrow \alpha>h(R) X=\lambda g(R)$. 
case but constant in the former, stock dependent harvest costs push the economically feasible resource stock range upwards. Or in other words: for a high harvest cost parameter, the (discounted) market price of the resource stock, which is the difference between the market price of the resource harvest and wagedependent harvest costs, is negative for some smaller resource stock values: $q-w h(R)<0 \Leftrightarrow \alpha<\lambda g(R) / R$. The reason for that finding is that the total harvesting effort - which now equals the fixed harvest cost parameter multiplied by average resource productivity - are largest for small values of the resource stock.

\section{Existence of stationary state market equilibrium}

Having established that the whole range of biologically feasible resource stock values, i.e. $R \in\left(0, R_{\max }\right)$ is also economically feasible in the model without harvest costs but not in the model variants with harvest costs, we now investigate the existence, uniqueness and asymptotic stability of the stationary state resource stock for that case.

\subsection{Reference model without harvest cost}

For a nontrivial stationary state to exist and to be asymptotically stable, it is sufficient that the left hand side of (13), denoted by $\operatorname{LHSO}(R)$, cuts the right hand side, $\operatorname{RHS} 0(R)$, from below at the intersection point.

As summarized in Proposition 2, this is essentially the case if the slope of the left hand side at the origin is flatter than the slope of the right hand side.

Proposition 2 (Existence, uniqueness, and stability without harvest cost)

For $h(R)=0$ a unique and asymptotically stable nontrivial stationary state solution $R \in\left(0, R_{\text {max }}\right)$ with $p>0$ exists if $1-(1-\gamma) r>0$ and $\lim _{R \rightarrow>0^{+}} \operatorname{LHSO}^{\prime}(R)$ $\lim _{R \rightarrow 0^{+}} \operatorname{RHSO}^{\prime}(R) \Leftrightarrow \alpha(1+r)<[1-\gamma(1-\alpha)] r$.

Proof 2: See Appendix A.2.

According to Proposition 2, two conditions are sufficient for the existence of a stationary state market equilibrium. For being able to apply the intermediate value theorem, we need to ensure that at $R=R_{\text {max }} \operatorname{RHS} 0(R)>\operatorname{LHSO}(R)$ and that the opposite holds at the origin. Since $\operatorname{RHS} 0(R)=0$ at $R=R_{\max }$, it is necessary that $\operatorname{LHS} 0(R)>0$ at $R=R_{\max }$ which leads to the first condition: $1-(1-\gamma) r>0$. Moreover, since $\operatorname{LHS} 0(0)=\operatorname{RHS} 0(0)=0$ at the origin, it is required that the slope of $\operatorname{LHSO}(R)$ in the neighborhood of the origin is smaller than the slope of $\operatorname{RHS} 0(R)$ or equivalently that $\alpha(1+r)<[1-\gamma(1-\alpha)] r$.The economic intuition for the first condition is that the aggregate of young and old household consumption has to be positive at $R_{\max }$, and hence also for all other resource stock values (see eqs. (11)(12) above). The second condition requires that the additional output generated by a marginal increase in resource input due to a marginal increase of the resource 
stock has to be met by intertemporal household savings sufficiently large to allow for that increased use of the resource stock in resource processing. Note that this condition is rather similar to the constraint on capital use in an OLG model with physical capital as the only asset (for the corresponding condition, see Galor and Ryder (1989)).

Figures 1-2 illustrate the stationary state market solution which, depending on parameter values, either lies to the left of the maximum sustainable yield resource stock, $R_{M S Y}=R_{\max } / 2$ (Fig. 1), or to the right of it (Fig. 2). ${ }^{14}$

Fig. 1. A unique and asymptotically stable stationary state $R<R_{M S Y}$ in model without harvest cost

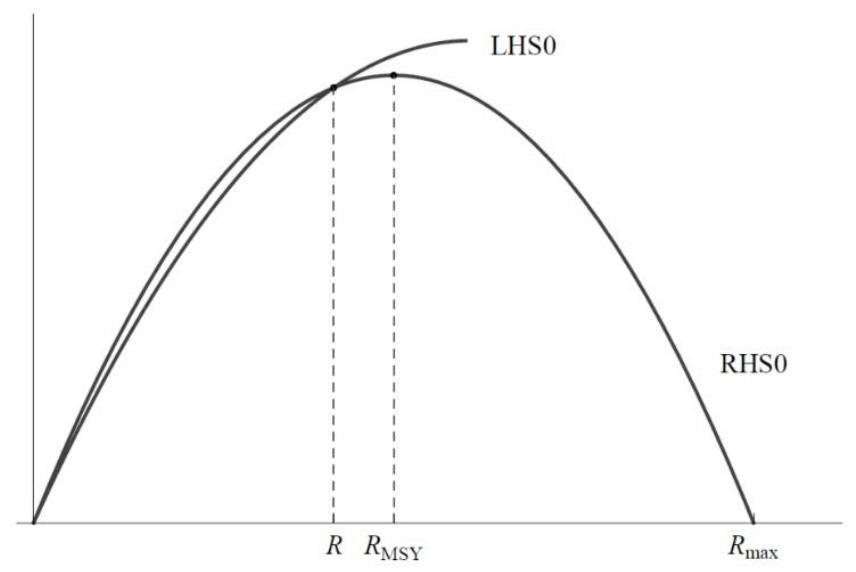

Fig. 2. A unique and asymptotically stable stationary state $R>R_{M S Y}$ in model without harvest cost

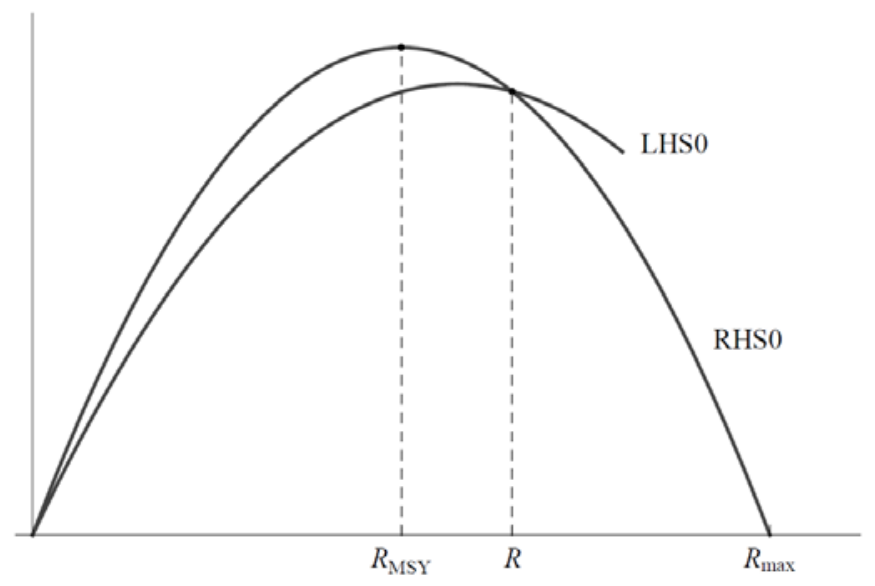

14 The figures are drawn for illustrative purposes based on the following parameter set: $\alpha=0.3, r=1.4, R_{\max }=10, \lambda=0$. In Fig. $1, \beta=0.6$, while $\beta=0.9$ in Fig. 2. 


\subsection{Model with constant unit harvest cost}

For constant unit harvest cost, economic feasibility may be violated over some ranges of biologically feasible resource stock values. Thus, we need to distinguish two cases for the existence of an asymptotically stable stationary state resource stock.

Proposition 3 (Existence, uniqueness, and stability with constant unit harvest cost)

For $h(R)=\lambda$, a unique and asymptotically stable nontrivial stationary state solution with $p>0$ exists if $\lambda<(4 \alpha) /\left(r R_{\max }\right), 1-(1-\gamma) r>0$, and moreover $(1+r) \alpha<[1-\gamma(1-\alpha)] r$, or if $\lambda \geq(4 \alpha) /\left(r R_{\max }\right)$.

Proof 2: See Appendix A.2.

By comparing Proposition 3 to Proposition 2 it can be seen that the slope condition in the model without harvest cost translates to the similar condition in the model with relatively small constant unit harvest costs (see Fig. 3). ${ }^{15}$

Fig. 3. A unique and asymptotically stable stationary state $R<R_{M S Y}$ in model with small constant unit harvest cost

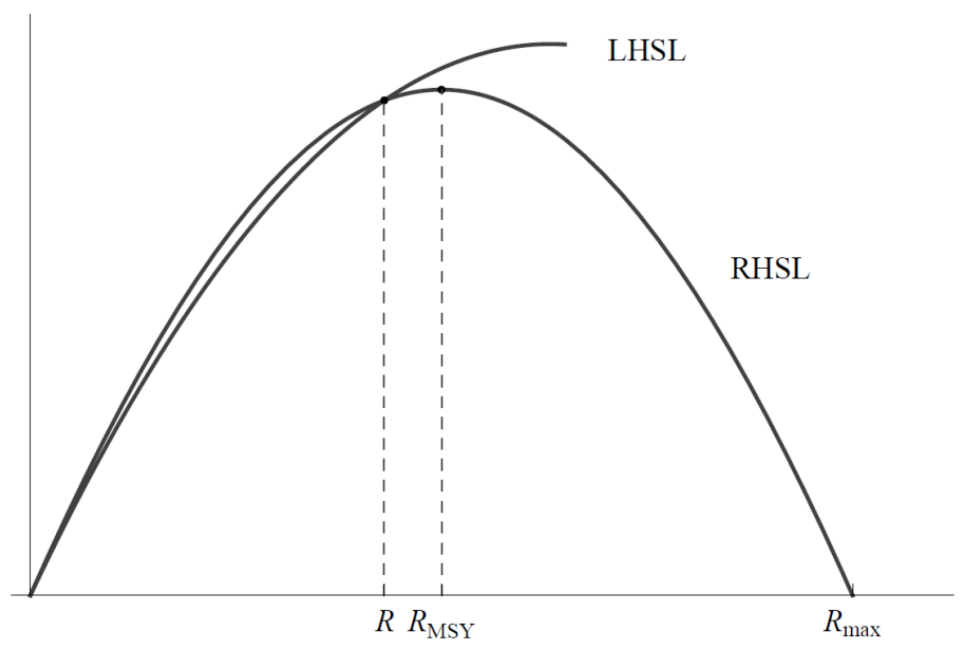

15 Fig. 3 is drawn for $\lambda=0.014$, and Fig. 4 for $\lambda=0.09$. For both figures, $\beta=0.55$. All other model parameters are set as for Fig. 1. 
Fig. 4. A unique and asymptotically stable stationary state $R>R_{M S Y}$ in model with relatively large constant unit harvest cost; the gray shaded area indicates where the resource stock price would be negative

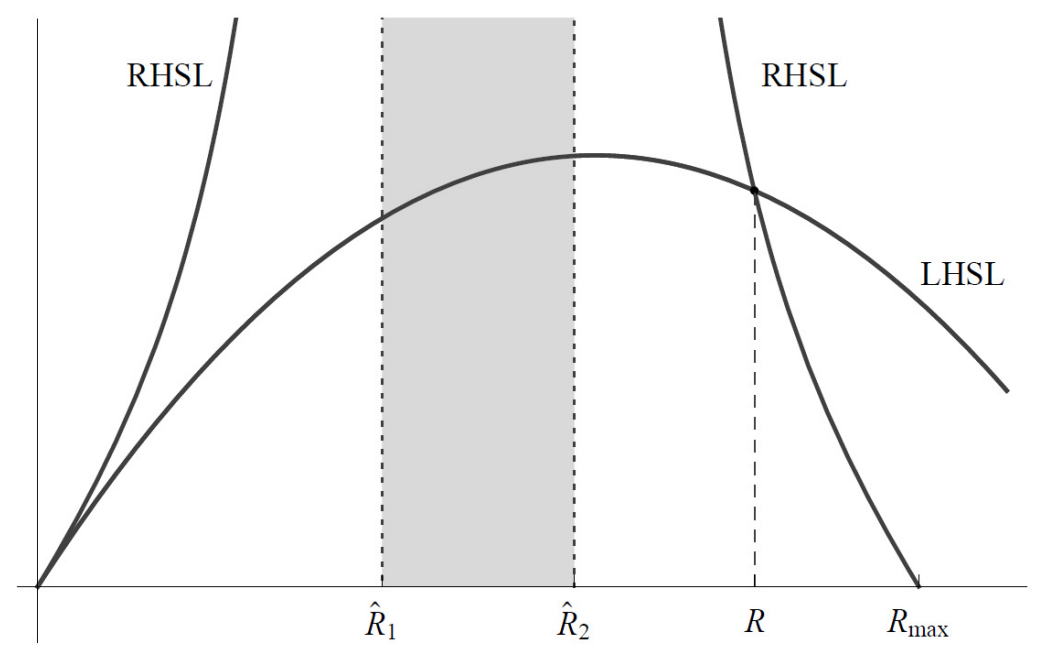

But in contrast to the model without harvest cost, the positivity of the resource stock price $p$ is no longer fulfilled for all biologically feasible resource stocks as Fig. 3 illustrates. While both to the left of $\hat{R}_{1}$ and to the right of $\hat{R}_{2}$ the resource stock price would be positive, the unique, and asymptotically stable stationary state market equilibrium is found at the right arm of RHSL. This stationary state is characterized by a relatively high harvest cost parameter, i.e. $\lambda>(4 \alpha) /\left(r R_{\max }\right)$ which induces a low harvest level and a high stationary state resource stock.

The economic intuition of this result is that when the harvest cost parameter is large, decision makers have a higher incentive to keep the resource stock large because for larger resource stocks and consequently small harvest volumes the harvesting effort is smaller than the production elasticity of harvest input in resource processing. In contrast, when the harvest cost parameter is small, harvesting volumes are large and hence the harvesting effort is larger than the production elasticity of harvesting input in resource processing.

Since Krutilla and Reuveny (2004) find multiple solutions in a one-sector ILA model due to harvest cost which impact on the resource stock regeneration while Elíasson and Turnovsky (2004) do not in a two-sector ILA model with labor using harvest cost, it remains to be discussed whether harvest costs can lead to multiple solutions in a resource based OLG framework. In our model setting with log-linear utility and Cobb-Douglas technology, the answer is no - on the one hand due to labor using harvest costs and on the other due to log-linear utility and Cobb-Douglas production technology (as in OLG models with endogenous labor supply: see LloydBraga et al. (2007)). We will show in the next section that this result carries also over to the case of inversely stock dependent harvest cost. 


\subsection{Model with inversely stock dependent harvest cost}

As for constant unit harvest cost, economic feasibility may be violated over some ranges of biologically feasible resource stock values. Thus, we need to distinguish now two cases for the existence of a stationary state resource stock.

Proposition 4 (Existence, uniqueness, and stability with inversely stock dependent harvest cost)

For $h(R)=\lambda / R$, a unique and asymptotically stable nontrivial stationary state solution with $p>0$ exists if $\lambda<\alpha / r, 1-(1-\gamma) r>0$ and moreover $1+r<\{(1-\gamma)[1-(1-\alpha) \lambda r]+\gamma \alpha-\lambda r\} r /(\alpha-\lambda r)$, or if $\lambda \geq \alpha / r$.

Proof 4: See Appendix A.3.

Again, the first case $(\lambda<\alpha / r)$ of Prop. 4 is a generalization of the slope condition in Prop. 2 (model without harvest costs). As a consequence of stock dependent harvest costs, the first case (small harvest cost parameter) is valid for a larger range of $R$ values as compared to the case with constant unit harvest costs (Fig. 5). This is the case as inverse stock dependent harvest cost imply for a small resource stock that unit harvest costs are high while they decrease with a larger resource stock.

Fig. 5. A unique and asymptotically stable stationary state $R<R_{M S Y}$ in model with stock dependent harvest cost and a small harvest cost parameter

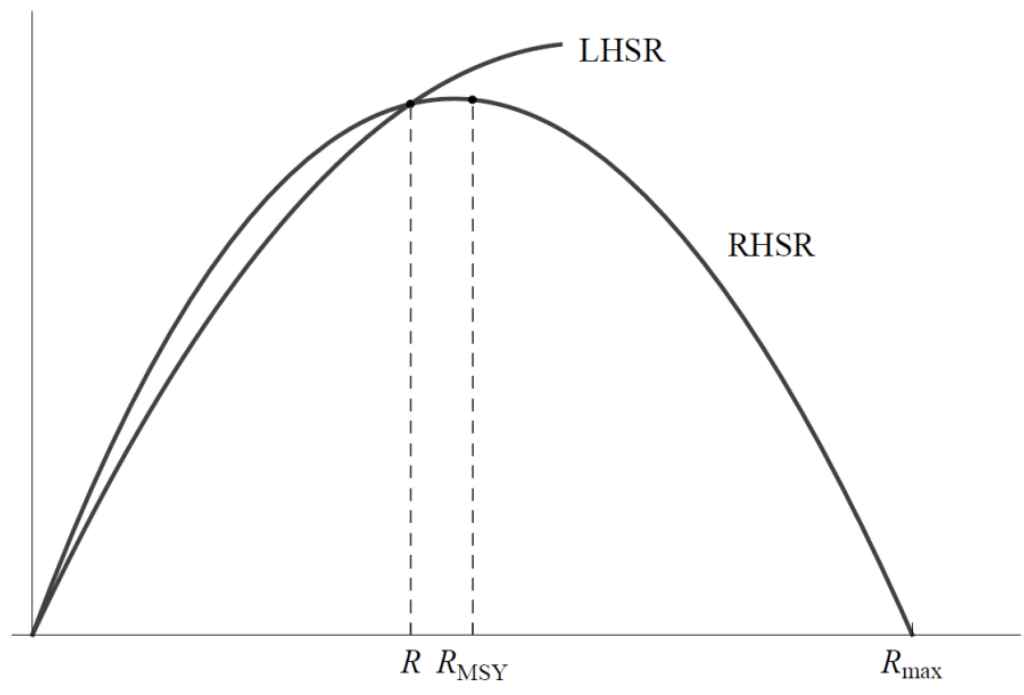


Fig. 6. A unique and asymptotically stable stationary state $R>R_{M S Y}$ in model with stock dependent harvest cost and a relatively large harvest cost parameter; the gray shaded area indicates where the resource stock price would be negative

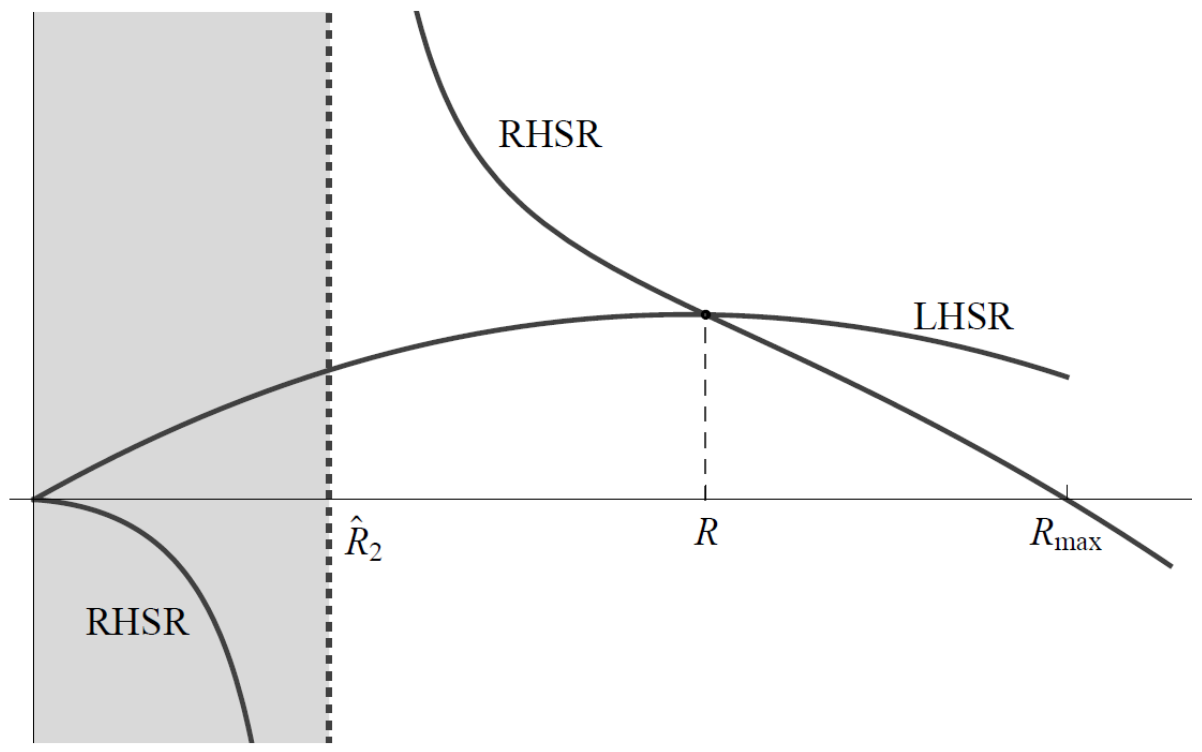

For the second case (large harvest cost parameter), illustrated in Fig. 6, again no slope restriction is necessary. Yet, relative to the case with constant unit harvest cost, the harvest cost parameter needs to be larger when harvest costs depend inversely on the resource stock. The reason is again that for a large resource stock, average harvest costs decline with a larger resource stock - an effect which cannot emerge when harvest costs only depend on harvest volume but not on the resource stock.

\section{Intergenerational efficiency of stationary state market equilibrium}

Knowing that a unique and asymptotically stable stationary state exists, we investigate when the stationary state market solution is intergenerationally efficient. This is particularly relevant given the fact that the nontrivial stationary state solutions may or may not be efficient in an OLG model with a renewable resource even without harvest costs (Koskela et al., 2002).

To derive the conditions for stationary intergenerational efficiency, we set up the problem of a social planner who maximizes utility of each individual living in the stationary state and require that the utility of the oldest generation alive in the initial period (denoted by subscript 0 ) achieves a predefined level: ${ }^{16}$

16 Koskela et al. (2002) alternatively put the utility function of the initially old generation with a positive weight into the welfare function of the social planner. 
$\max u\left(C^{1}, C^{2}\right)=\ln C^{1}+\beta \ln C^{2}$

subject to

$$
\begin{aligned}
& \text { (i) } \ln C_{0}^{2}=\ln \left(C_{0}^{2}\right)^{\circ}, \\
& \text { (ii) } C^{1}+C_{0}^{2}=X^{\alpha}\left[1-h\left(R_{0}\right) X\right]^{(1-\alpha)}, \\
& \text { (iii) } C^{1}+C^{2}=X^{\alpha}[1-h(R) X]^{(1-\alpha)}, \\
& \text { (iv) } X=g(R), \\
& \text { (v) } R+X=R_{0}+g\left(R_{0}\right), \\
& \text { (vi) }\left(C_{0}^{2}, C^{1}, C^{2}\right) \geq 0, R \geq 0, X \geq 0 .
\end{aligned}
$$

where $R_{0}>0$ is the resource stock owned by the initially old generation.

To see whether individual utility and profit maximization in perfectly competitive markets lead to intergenerational efficiency, we compare household and firm first order conditions (2)-(9) as well as market clearing conditions in the stationary state market equilibrium to the intergenerational efficiency conditions (see equations (A.5) in the Appendix). We start again with the reference case without harvest cost before proceeding to linear and inversely stock dependent harvest cost.

\subsection{Reference case without harvest cost}

Proposition 5 states under which conditions the stationary market equilibria without harvest cost are intergenerationally efficient and considers Diamond's (1965) 'Golden Age', in which the utility of the initially old generation is disregarded as constraint for utility maximization of the young generation in the stationary state, as a special case.

\section{Proposition 5 (Intergenerational efficiency without harvest cost)}

For $h(R)=0$ the stationary market equilibrium $R$ from (10) is intergenerationally efficient if $g^{\prime}(R)>0$, and it is Golden Age if $\mu_{-1}^{C}=0$ and $g^{\prime}(R)=0$. Otherwise, the stationary state market equilibrium is intergenerationally inefficient.

Proof 5: See Appendix A.5.

The two possible cases are illustrated by Figs. 1-2. In Fig. 1, the stationary state market equilibrium is intergenerationally efficient - the stationary resource stock exhibits, because of the no-arbitrage condition, a positive own rate of return (underaccumulation of the resource stock occurs). This resource stock is below the Golden Age resource stock which coincides with the maximum sustainable yield level $R_{M S Y}$. 
The opposite case is illustrated by Fig. 2 in which $\quad g^{\prime}(R)<0 \Leftrightarrow R>R_{M S Y}$ and hence the stationary state market equilibrium is intergenerationally inefficient. Thus, a central planner could increase the welfare of the present and all future generations by a reduction in resource accumulation.

\subsection{Constant unit harvest cost}

In case of constant unit harvest cost, the constant harvest cost parameter $\lambda$ enters both the stationary market equilibrium and the intergenerational efficiency conditions. As a consequence, a specific value of the harvest cost parameter denoted by $\lambda^{E}$ determines the range of stationary market equilibria which are intergenerationally efficient. This is summarized in Prop. 6. cost)

Proposition 6 (Intergenerational efficiency with constant unit harvest

If for $h(R)=\lambda$ unit harvest cost satisfies $0<\lambda<\lambda^{E}$, where $\lambda^{E} \equiv[8 \alpha-$ $4(1-\gamma) r] /\left\{r[2-(1-\gamma) r] R_{\max }\right\}$, then the stationary market equilibrium is intergenerationally efficient. The Golden Age applies when $\lambda=\lambda^{E}$. When $\lambda>\lambda^{E}$, the stationary market equilibrium is intergenerationally inefficient.

Proof 6: See Appendix A.6.

The two cases are illustrated in Figs. 3-4. In Fig. 3, $\lambda<\lambda^{E}$ which is equivalent to $R<R_{\max } / 2=R_{M S Y}$, and hence the stationary market equilibrium is intergenerationally efficient. Note the similarity here to the model without harvest costs: intergenerational efficiency is obtained when the own rate of return on the resource stock $g^{\prime}(R)$ is positive in the stationary state market equilibrium. The opposite case with a negative rate of return, i.e. where $\lambda>4 \alpha /\left(r R_{\max }\right)>\lambda^{E}$ holds, is illustrated in Fig. 4 and hence the stationary market equilibrium is intergenerationally inefficient.

To understand why a stationary market solution with large harvest cost parameter $\lambda$ is intergenerationally inefficient, it is useful to evaluate the consequences which a higher harvest cost parameter has for the equilibrium resource stock. The higher harvesting costs, the more costly it is to harvest, the lower is the resource harvest and its use in resource processing. As a consequence, most of labor will be devoted to resource processing instead of harvesting. But due to decreasing productivity of labor in resource processing, output and hence welfare could be increased when more labor would be devoted to harvesting.

\subsection{Inversely stock dependent harvest cost}

In case of inversely stock dependent harvest cost, unit harvest cost are not constant but decrease with increasing resource stock value. In contrast to the case of constant unit harvest cost, a critical value of the harvest cost parameter $\lambda^{E}$ cannot 
be stated in general except for the Golden Age case. Instead, the value of the harvest cost parameter ensures that the shadow prices corresponding to constraints (A.5c) and (A.5d) in Appendix A.5 are positive. This is summarized in Prop. 7.

\section{cost)}

Proposition 7 (Intergenerational efficiency with stock dependent harvest

Let $h(R)=\lambda / R$. For all $\lambda>0$ such that (7)-(9) allow for $\phi_{0}^{R} / \phi^{R}>0$ and $\phi_{0}^{Y} / \phi^{Y}>0$, the stationary state market equilibrium is intergenerationally efficient. The Golden Age applies when $\lambda=\lambda^{E}$, where $\lambda^{E} \equiv(1-\gamma)[2 \alpha-(1-\gamma) r]$ $/\{[(1-\gamma) r-\alpha][1+\alpha-(1-\gamma) r]\}$, and $R^{E} \equiv\left(\alpha R_{\max }\right) /[(1-\gamma) r]$. When $\lambda>\alpha / r$, the stationary market equilibrium is intergenerationally inefficient.

Proof 7: See Appendix A.7.

Although complicated, one can see from condition (A.7) in the Appendix A.7 that for intergenerational efficiency $\left(\phi^{R} / \phi^{Y}>0\right)$ a strictly positive own rate of return on natural capital is not necessary. The two cases of Prop. 7 are again illustrated in Figs. 5-6. In Fig. 6, the harvest cost parameter is large $\left(\lambda>\alpha / r>\lambda^{E}\right)$ and therefore the stationary market equilibrium is intergenerationally inefficient. For a harvest cost parameter $\lambda$ such that $\phi_{0}^{R} / \phi^{R}>0$ and $\phi_{0}^{Y} / \phi^{Y}>0$, the stationary market equilibrium is intergenerationally efficient, as illustrated in Fig. 5.

Comparing these results to the model without harvest cost where a positive own rate of return on the resource stock is required for intergenerational efficiency, it can be concluded that a weaker but far more complicated condition is needed in the model with inversely stock dependent harvest costs. The reason for that is that inversely stock dependent harvest costs have additional effects on both the size of the stationary state resource stock and the harvest level.

\section{Discussion and conclusions}

This paper compared different specifications of harvest cost in an OLG model with a renewable natural resource similar to Koskela et al. (2002). The first key insight is that zero harvest costs must not be considered as a special case of constant unit harvest costs or inversely stock dependent harvest cost in this type of model, essentially for two reasons.

First, because of resource harvest competing with resource processing for labor, some biologically feasible resource stocks would eventually lead to a negative resource stock price and hence would be economically infeasible. In particular, for a positive resource stock price the production elasticity of resource input (or, equivalently, the resource input production share) has to exceed total harvest effort for a given resource stock. For constant unit harvest costs this condition is fulfilled when the resource stock is small or large but not for intermediate values because with an intermediate sized resource stock harvest volumes and hence total harvest costs are large. In contrast, when harvest costs additionally depend inversely on the 
stock, unit harvest costs decline with a larger resource stock and hence the feasibility condition requiring a sufficiently larger production elasticity of resource input is easier fulfilled for a larger resource stock.

Second, the magnitude of harvest cost, and in particular of the size of the harvest cost parameter, is also instrumental for the existence of a stationary state solution. While without harvest costs a slope condition needs to hold at the origin to ensure the existence of a stationary state, no such condition is required with a sufficiently large harvest cost parameter. As for feasibility, the argument is again that higher total harvest costs imply a comparatively large stationary state resource stock which lies to the right of a strictly positive pole and hence no restrictions at the origin are required.

In addition to investigating the difference to the model without harvest cost, our objective was to study the potentially different impacts of alternative specifications of harvest costs. Here we find that inversely stock dependent harvest cost favor the existence of a nontrivial stationary state because harvest costs increase with a smaller resource stock. Thus, while unit harvest costs are small for a large resource stock, they become large for a small resource stock which provides a disincentive for overexploitation of the resource stock. This effect is not present when harvest costs depend only on the harvest volume but not the stock.

Moreover, when comparing the two types of harvest costs, there is another important difference in regard to intergenerational efficiency. While the efficiency condition requiring positivity of the own rate of return on the resource stock carries over to the model with constant unit harvest costs, this is not required in the model with inversely stock dependent harvest cost. In particular, only a weaker condition needs to hold and hence a stationary state market equilibrium in the model with stock dependent harvest cost may also be intergenerationally efficient even when the own rate of return is negative, i.e. when the resource stock lies to the right of the maximum sustainable yield level.

Yet, despite inversely stock dependent harvest cost, the higher the harvest cost parameter is the more likely a stationary state market equilibrium may eventually be intergenerationally inefficient. This is due to the fact that the higher total harvest costs the lower is resource harvest and the use of resource harvest in resource processing. As a consequence, most of labor will be devoted to resource processing instead of harvesting. But due to decreasing productivity of labor in resource processing, output and hence welfare could be increased when more labor would be devoted to harvesting.

The analytical limitations of this paper are rather obvious: we are working with widely-used but rather specific functional specifications of the intertemporal utility function, the production function, the regeneration and the harvest cost function. We conjecture that our main substantial results will go through even under more general functional specifications but it is open to prove this conjecture. Remaining within our rather specific functional specifications the following directions for extending the scope of this paper are easily identified. First, instead of linear harvest cost, a quadratic specification as in Maroto et al. (2012) could be used. Second, the inverse impact of the resource stock could be reversed such that harvest costs increase with the resource stock, a specification suitable e.g. for species-rich ecosystems like tropical forests. Finally, also fixed costs could be considered, which may give rise to non-convexities (as in Kennedy and Barbier, 2015). 


\section{Reference}

Bednar-Friedl, B., Farmer, K. (2013) Time consuming resource extraction in an overlapping generations economy with capital, Journal of Economics, 110 (3), 203-224

Bjørndal T., Conrad J. M., Salvanes K. G. (1993) Stock size, harvesting costs, and the potential for extinction: the case of sealing, Land Economics, 69 (2), 156-167

Bréchet T., Lambrecht S., (2011) Renewable resource and capital with a joy-of-giving resource bequest motive, Resource and Energy Economics, 33 (4), 981-994

Brown G. M. (2000) Renewable natural resource management and use without markets, Journal of Economic Literature, 38 (4), 875-914

Clark C. W. (1990) Mathematical Bioeconomics: The Optimal Management of Renewable Resources, $2^{\text {nd }}$ Edition, Wiley, New York

Clark C. W., Munro, G. R. (1975) The economics of fishing and modern capital theory: a simplified approach, Journal of Environmental Economics and Management 2, 92106

Conrad J. M. (1999) Resource Economics, Cambridge University Press, Cambridge, New York

De la Croix D., Michel P. (2002) A Theory of Economic Growth. Dynamics and Policy in Overlapping Generations, Cambridge University Press, Cambridge, New York

Diamond P. (1965) National debt in a neoclassical growth model, American Economic Review 55, 1126-1150

Elíasson L., Turnovsky, S. J. (2004) Renewable resources in an endogenously growing economy: balanced growth and transitional dynamics, Journal of Environmental Economics and Management 48, 1018-1049

Farmer, K. (2000) Intergenerational natural-capital equality in an overlappinggenerations model with logistic regeneration, Journal of Economics, 72 (2), 129152

Galor O., Ryder H. E. (1989) Existence, uniqueness, and stability of equilibrium in an overlapping-generations model with productive capital, Journal of Economic Theory 49, 360-375

Grafton R., Kompas T., Hilborn R. (2007) Economics of overexploitation revisited, Science 318 (5856), 1601

Heaps T., Neher P. A. (1979) The economics of forestry when the rate of harvest is constrained, Journal of Environmental Economics and Management 6, 297-319

Howarth R., Norgaard R. (1990) Intergenerational resource rights, efficiency and social optimality, Land Economics 66 (1), 1-11

Kennedy C. J., Barbier, E. (2015) Renewable resource harvesting under correlated biological and economic uncertainties: Implications for optimal and second-best management, Environmental \& Resource Economics, 60 (3), 371-393

Koskela E., Ollikainen M., Puhakka, M. (2002) Renewable resources in an overlapping generations economy without capital, Journal of Environmental Economics and Management, 43 (3), 497-517

Krautkraemer J. A., Batina R. G. (1999) On sustainability and intergenerational transfers with a renewable resource, Land Economics, 75 (2), 167-184

Krutilla K., Reuveny R. (2004) A renewable resource-based Ramsey model with costly resource extraction, Environmental and Resource Economics 27, 165-185 
Levhari D., Michener R., Mirman L. J. (1981) Dynamic programming models in fishing: competition, American Economic Review, 71 (4), 649-661

Lloyd-Braga T., Nourry C., Venditti A. (2007) Indeterminacy in dynamic models: When Diamond meets Ramsey, Journal of Economic Theory 134, 513-536

Maroto J. M., Moran, M., Sandal L. K., Steinshamn S. I. (2012) Potential collapse in fisheries with increasing returns and stock-dependent costs, Marine Resource Economics, 27 (1), 43-63

Mourmouras A. (1991) Competitive equilibria and sustainable growth in a life-cycle model with natural resources, Scandinavian Journal of Economics, 93 (4), 585591

Olson L. J., Knapp K. C. (1997) Exhaustible resource allocation in an overlapping generations economy, Journal of Environmental Economics and Management 32, 277-292

Olson L. J., Roy, S. (1996) On conservation of renewable resources with stockdependent return and non-concave production, Journal of Economic Theory 70, 133-157

Schaefer M. B. (1954) Some aspects of the dynamics of populations important to the management of commercial marine fisheries, Bulletin of Inter-American Tropical Tuna Commission 1, 25-56

Shell K. (1971) Notes on the economics of infinity, Journal of Political Economy 79, 1002-1012

Smith V. L. (1968) Economics of production from natural resources, American Economic Review 58, 409-432

Valente S. (2008) Intergenerational transfers, lifetime welfare, and resource preservation, Environment and Development Economics, 13 (1), 53-78 


\section{A. Appendix}

\section{A.1 Proof to Proposition 1}

To show how the denominator of (10) is decisive for the positivity of the resource stock price $p$, we substitute for the firm's first order conditions in (8) and evaluate the resulting expression at the stationary state:

$$
p=\frac{\left\{[\alpha-h(R) g(R)]\left[1+g^{\prime}(R)\right]-(1-\alpha) h^{\prime}(R) g(R)^{2}\right\} g(R)^{\alpha}[1-h(R) g(R)]^{(1-\alpha)}}{g(R)[1-h(R) g(R)]}
$$

Inspecting the numerator of (A.1) reveals that all expressions are clearly positive except for $[\alpha-h(R) g(R)]$. Thus, a necessary and sufficient condition for a positive stationary state resource stock price, and hence an economically feasible resource stock, is that $[\alpha-h(R) g(R)]>0$.

Focusing first on the case of linear harvest cost, i.e. $h(R)=\lambda$, the feasibility requirement reduces to $[\alpha-\lambda g(R)]>0$, and implies that the right hand side of (13) exhibits two poles between which the resource stock price would become negative. With inversely stock dependent harvest cost, the economic feasibility requirement reduces to $[\alpha R-\lambda g(R)]>0$, and thus one pole results for (13), and left of this pole the resource stock price would become negative. Finally, without harvest cost the feasibility requirement is equal to $\alpha>0$, and thus no pole emerges. Hence, without harvest cost the resource stock price is positive for the whole range of biologically feasible resource stock values $\left(R \in\left(0, R_{\max }\right)\right)$.

For $h(R)=\lambda$, denote the left hand side of (13) by $\operatorname{LHSL}(R)$ and the right hand side by $\operatorname{RHSL}(R)$ and the denominator of the latter by $\operatorname{BL}(R) \equiv \alpha-\lambda g(R)$. For logistic regeneration, the poles of $\mathrm{BL}(R)=0$ can be calculated as $\hat{R}_{1,2}=R_{\max } / 2 \pm$ $\sqrt{\left[\lambda r R_{\max }\left(\lambda r R_{\max }-4 \alpha\right)\right] /(2 \lambda r)}$. Both solutions are real if $\lambda r R_{\max }-4 \alpha \geq 0 \Leftrightarrow \lambda \geq$ $(4 \alpha) /\left(r R_{\max }\right)$. If on the other hand $\lambda r R_{\max }-4 \alpha<0$, no pole emerges for $\operatorname{RHSL}(R)$.

For $h(R)=\lambda / R$, denote again the left and right hand side of (13) by $\operatorname{LHSR}(R) \equiv \Psi(R)$ and by $\operatorname{RHSR}(R) \equiv g(R)\{[1-\gamma(1-\alpha)] R-[1+(1-\gamma)(1-\alpha)]$ $g(R) \lambda\} / \operatorname{BR}(R)$ where $\operatorname{BR}(R) \equiv[\alpha R-\lambda g(R)]$. By setting $\operatorname{BR}(R)=0$, we find two poles of $\operatorname{RHSR}(R): \hat{R}_{1}=0$ and $\hat{R}_{2}=\left[(\lambda r-\alpha) R_{\text {max }}\right] /(\lambda r)$. For $\lambda r=\alpha, \hat{R}_{1}=\hat{R}_{2}=0$, while for $\lambda>\alpha / r$ only the second pole $\hat{R}_{2}$ exists. Q.E.D.

\section{A.2 Proof to Proposition 2}

For the proof of the existence of the stationary state solution, note that at the origin, $\operatorname{LHSO}(0)=\operatorname{RHSO}(0)=0 \quad$ but by assumption $\lim _{R->0^{+}} \operatorname{LHSO}^{\prime}(R)<$ $\lim _{R->0^{+}} \operatorname{RHSO}^{\prime}(R)$. On the other hand, $\operatorname{LHSO}\left(R_{\max }\right)=[1-(1-\gamma) r] R_{\max }$ and 
$\operatorname{RHS} 0\left(R_{\max }\right)=0$ and hence, by assumption of $[1-(1-\gamma) r]>0, \operatorname{LHS} 0\left(R_{\max }\right)>$ $\operatorname{RHSO}\left(R_{\max }\right)$. Since both $\operatorname{LHSO}(R)$ and $\operatorname{RHSO}(R)$ are continuous functions on $\left[0, R_{\max }\right]$, an intermediate value theorem ensures the existence of a $0<R<R_{\max }$ such that $\operatorname{LHSO}(R)=\operatorname{RHSO}(R)$.

For the uniqueness of the stationary state solution, we need to distinguish the range of $R$ on which $\operatorname{LHS} 0(R)$ and/or $\operatorname{RHS} 0(R)$ are monotonically increasing or decreasing. Assume first that the model parameters are such that the stationary state solution lies in $\left(0, R_{\max } / 2\right]$. Knowing that both $\operatorname{LHS} 0(R)$ and $\operatorname{RHS} 0(R)$ are monotonically increasing in $\left(0, R_{\text {max }} / 2\right]$ and moreover that $\lim _{R \rightarrow R_{\max } / 2} \mathrm{LHSO}^{\prime}(R)$ $=1-r(1-\gamma)>\lim _{R \rightarrow R_{\text {max }} / 2} \operatorname{RHSO}^{\prime}(R)=0$, functions $\operatorname{LHSO}(R)$ and $\operatorname{RHSO}(R)$ intersect exactly once on the interval $\left(0, R_{\max } / 2\right]$.

If, on the other hand, the stationary state lies in $\left(R_{\max } / 2, R_{\max }\right), \operatorname{RHS} 0(R)$ is monotonically decreasing. If $\operatorname{LHS} 0(R)$ is increasing, the intersection point with $\operatorname{RHSO}(R)$ is unique. In the opposite case of decreasing $\operatorname{LHS} 0(R)$, the slope of $\operatorname{RHSO}(R)$ is larger than that of $\operatorname{LHSO}(R)$ since $\operatorname{LHSO}\left(R_{\text {max }}\right)=1-r(1-\gamma)>$ $\operatorname{RHS0}\left(R_{\max }\right)=0$.

For local asymptotic stability of the stationary state solution, we have to show that $0<d R_{t+1} / d R_{t}<1$ holds at the stationary state $R$ which is equivalent to $d R_{t+1} / d R_{t}=1+g^{\prime}(R)-d X_{t} / d R_{t}>0$ and $g(R)<d X_{t} / d R_{t}$. In order to show that $1+g^{\prime}(R)-d X_{t} / d R_{t}>0$, we investigate the intertemporal equilibrium dynamics:

$$
\Psi\left(R_{t}\right)=\frac{X_{t} R_{t}[1-\gamma(1-\alpha)]-\left(X_{t}\right)^{2}\left[h\left(R_{t}\right) R_{t}-(1-\gamma)(1-\alpha) h^{\prime}\left(R_{t}\right)\left(R_{t}\right)^{2}\right]}{\left(R_{t}\right)^{2}\left[\alpha-h\left(R_{t}\right) X_{t}\right]} .
$$

Considering that $h(R)=0 \quad$ in (A.2) gives $X_{t}=\alpha /(\alpha+\beta)$ $\left\{R_{t}+g\left(R_{t}\right)+\beta\left[1+g^{\prime}\left(R_{t}\right)\right] R_{t}\right\}$ which yields for the first derivative $d X_{t} / d R_{t}(R)=$ $\alpha /(\alpha+\beta)\left\{\left[1+g^{\prime}(R)\right](1+\beta)-\beta g^{\prime \prime}(R) R\right\}$ and hence $d R_{t+1} / d R_{t}(R)=\left[1+g^{\prime}(R)\right] \beta$ $(1-\alpha) /(\alpha+\beta)-(\alpha \beta) /(\alpha+\beta) g^{\prime \prime}(R) R>0$ since $g^{\prime \prime}(R)<0$.

In order to show that $-g^{\prime}(R)<d X_{t} / d R_{t}(R)$, we have to distinguish the range of $R$ on which $g^{\prime}(R) \geq 0$ from that on which $g^{\prime}(R)<0$. Assume first that the model parameters are such that the stationary state solution lies in $\left(0, R_{\max } / 2\right)$.Then, clearly $g^{\prime}(R) \geq 0$ and $\operatorname{RHSO}^{\prime}(R) \geq 0$. This is also true for $\operatorname{LHSO}^{\prime}(R)$, because LHS0 $^{\prime}(R)=1+r+[2(\gamma-2) r R] / R_{\max }$ is positive for $R=R_{\max }$ and therefore a fortiori also positive for smaller $R$. Since moreover $\operatorname{RHS0}^{\prime}\left(R_{\text {max }} / 2\right)<\operatorname{LHS0}^{\prime}\left(R_{\text {max }} / 2\right)$ and by assumption $\lim _{R->0^{+}} \operatorname{LHSO}^{\prime}(R)<\lim _{R->0^{+}} \mathrm{RHSO}^{\prime}(R)$, it follows from continuity of $\operatorname{LHS0}^{\prime}(R)$ and $\operatorname{RHS0}^{\prime}(R)$ that for $R \in\left(0, R_{\text {max }} / 2\right) \quad \operatorname{LHSO}^{\prime}(R)>\operatorname{RHS0}^{\prime}(R)$ $\Leftrightarrow \alpha /(\alpha+\beta)\left\{(1+\beta)\left[1+g^{\prime}(R)\right]+\beta g^{\prime \prime}(R) R\right\}>g^{\prime}(R)$. 
Second, assume that the stationary state $R \in\left(R_{\max } / 2, R_{\max }\right)$. Clearly, $g^{\prime}(R)<0$ and $\operatorname{RHSO}^{\prime}(R)<0$. If moreover $\operatorname{LHSO}^{\prime}(R) \geq 0$, the claim that $\operatorname{LHSO}^{\prime}(R)>$ $\mathrm{RHSO}^{\prime}(R)$ is proven. If, on the other hand $\operatorname{LHSO}^{\prime}(R)<0$, the (negative) slope of $\operatorname{RHS} 0(R)$ is larger than the (negative) slope of $\operatorname{LHS} 0(R)$, because for $R=R_{\max }$ $\operatorname{LHS0}\left(R_{\text {max }}\right)=1-r(1-\gamma)>\operatorname{RHSO}\left(R_{\text {max }}\right)=0$ and thus $\operatorname{RHS0}^{\prime}(R)<\operatorname{LHS0}^{\prime}(R)$ holds a fortiori for $R \in\left(R_{\max } / 2, R_{\max }\right)$. Q. E. D.

\section{A.3 Proof to Proposition 3}

To proof the existence and uniqueness of the stationary states with constant unit harvest costs, according to Prop. 3 we have to distinguish for three cases:

i. Focusing first on the case $\lambda r R_{\max }-4 \alpha<0$, we have $\operatorname{BL}(R)>0$ for $R \in\left(0, R_{\max }\right]$. Analogously to the existence proof to Proposition 2 it is easy to verify that $\operatorname{LHSL}(0)=\operatorname{RHSL}(0)$ (see Fig. 3 ). On the other hand, when $[1-(1-\gamma) r]>0, \operatorname{LHSL}\left(R_{\max }\right)=[1-(1-\gamma) r] R_{\text {max }}>\operatorname{RHSL}\left(R_{\max }\right)=0$.

Since both functions are continuous on $R \in\left(0, R_{\max }\right]$ and by assumption $\lim _{R \rightarrow 0^{+}} \operatorname{LHSL}^{\prime}(R)<\lim _{R \rightarrow 0^{+}} \operatorname{RHSL}^{\prime}(R)$, at least one stationary state solution exists.

For the uniqueness of the stationary state, we need again to distinguish the range of $R$ on which $\operatorname{LHSL}(R)$ and $\operatorname{RHSL}(R)$ are monotonically increasing or decreasing. Assume first that the model's parameters ( $\lambda$ included) are such that the stationary state solution lies in $\left(0, R_{\max } / 2\right]$. We know from the proof of Proposition 2 that for $R \in\left(0, R_{\max } / 2\right] \operatorname{LHSL}^{\prime}(R)>0$ and also $\operatorname{RHSL}^{\prime}(R) \geq 0$ because $\lim _{R \rightarrow 0^{+}} \operatorname{RHSL}^{\prime}(R)=[1-(1-\alpha) \gamma] r / \alpha>0$ and $\lim _{R \rightarrow R_{\max } / 2} \operatorname{RHSL}^{\prime}(R)=0$. Since $\lim _{R \rightarrow R_{\max } / 2} \operatorname{LHSL}^{\prime}(R)>0$, functions $\operatorname{LHSL}(R)$ and $\operatorname{RHSL}(R)$ intersect once on the interval $\left(0, R_{\max } / 2\right]$.

On the other hand, for a stationary state $R \in\left(R_{\max } / 2, R_{\max }\right), \operatorname{RHSL}^{\prime}(R)$ is monotonically decreasing. If $\operatorname{LHSL}^{\prime}(R)>0$, the intersection point is unique. In the opposite case of $\operatorname{LHSL}^{\prime}(R)<0$, the slope of $\operatorname{RHSL}(R)$ is larger (in absolute terms) than that of $\operatorname{LHSL}(R)$ since $\operatorname{LHSL}\left(R_{\max }\right)=[1-r(1-\gamma)] R_{\max }$ $>\operatorname{RHSL}\left(R_{\max }\right)=0$. Thus, the intersection is unique, too.

ii. For the case of $\lambda r R_{\max }-4 \alpha=0$, there is one pole $\hat{R}=R_{\max } / 2$. Since $g(R)$ is maximal for $R=R_{\max } / 2$ and $\mathrm{BL}\left(R_{\max } / 2\right)=0$, it follows that $\mathrm{BL}(R)>0$ for all other admissible $R$. However, as $\lim _{R->0^{+}} \operatorname{LHSL}^{\prime}(R)<\lim _{R->0^{+}} \operatorname{RHSL}^{\prime}(R)$ and moreover $\lim _{R \rightarrow R_{\text {max }} / 2} \operatorname{RHSL}(R)=+\infty, \operatorname{RHSL}(R) \neq \operatorname{LHSL}(R)$ for all $R$ 
in $\left(0, R_{\max } / 2\right]$. To the right of the pole, i.e. $R \in\left(R_{\max } / 2, R_{\max }\right), \operatorname{RHSL}(R)$ decreases monotonically with larger $R$ with $\lim _{R->R_{\max }} / 2 \operatorname{RHSL}(R)=+\infty$ and $\lim _{R \rightarrow R_{\max }} \operatorname{RHSL}(R)=0$. On the other hand, $\operatorname{LHSL}^{\prime}\left(R_{\max } / 2\right)=0$ and $\operatorname{LHSL}\left(R_{\text {max }}\right)>0$. Since both $\operatorname{LHSL}(R)$ and $\operatorname{RHSL}(R)$ are continuous functions of $R \in\left(R_{\max } / 2, R_{\max }\right)$, an intermediate value theorem ensures a solution $\operatorname{LHSL}(R)=\operatorname{RHSL}(R)$. The solution is again unique because the slope of $\operatorname{RHSL}(R)$ is negative and the slope of $\operatorname{LHSL}(R)$ is positive or negative but in the latter case certainly smaller (in absolute terms) than that of $\operatorname{RHSL}(R)$.

iii. If $\lambda r R_{\max }-4 \alpha>0$, two poles $\hat{R}_{1}$ and $\hat{R}_{2}$ occur (see Fig. 3). It is not difficult to see that $\mathrm{BL}(R)>0$ for $R \in\left[0, \hat{R}_{1}\right) \cup\left(\hat{R}_{2}, R_{\max }\right)$ and $\mathrm{BL}(R)<0$ for $R \in\left[\hat{R}_{1}, \hat{R}_{2}\right]$. By an analogous argument as in case (ii), it can be shown that $\operatorname{RHSL}(R) \neq \operatorname{LHSL}(R)$ for $R \in\left[0, \hat{R}_{1}\right)$ while there is a unique solution in $\left(\hat{R}_{2}, R_{\max }\right)$.

In order to prove local asymptotic stability of the stationary state over the interval $\left(0, R_{\max } / 2\right]$ and $\left(R_{\max } / 2, R_{\max }\right) \quad$ we need to show that $0<d R_{t+1} / d R_{t}<1 \Leftrightarrow 1+g^{\prime}(R)-d X_{t} / d R_{t}(R)>0 \wedge g^{\prime}(R)<d X_{t} / d R_{t}(R)$. Deriving again $d X_{t} / d R_{t}(R)$ in (2) for the case of constant unit harvest cost yields:

$$
1+g^{\prime}(R)-d X_{t} / d R_{t}(R)=\frac{\left[1+g^{\prime}(R)\right] \alpha \beta(1-\alpha)-(\alpha-\lambda g(R))^{2} \beta g^{\prime \prime}(R) R}{\left[\alpha(\alpha+\beta)-2 \alpha(1+\beta) \lambda g(R)+(1+\beta) \lambda^{2} g(R)^{2}\right]} .
$$

The numerator of (A.3) is certainly positive because of $g^{\prime \prime}(R)<0$ but the sign of the denominator is not obvious. But in fact, the denominator is larger than zero because it is minimal at $g(R)=\alpha / \lambda$, since for this value of $g(R)$ the denominator of (A.3) equals $\alpha(1+\beta)(1-\alpha)>0$. Obviously, for all other values of $g(R)$ the denominator is larger and therefore $1+g^{\prime}(R)-d X_{t} / d R_{t}$ is larger than zero for all $R \in\left(0, R_{\max }\right)$.

To show that $g^{\prime}(R)<d X_{t} / d R_{t}$, we need to distinguish again the range of $R$ on which $g^{\prime}(R) \geq 0$ or $g^{\prime}(R)<0$. Consider first the case in which the stationary state solution lies in $\left(0, R_{\max } / 2\right]$ and hence $g^{\prime}(R) \geq 0$ and $\operatorname{RHSL}^{\prime}(R)>0$ since $\operatorname{RHSL}^{\prime}(R)$ $\lim _{R \rightarrow>0^{+}} \operatorname{RHSL}^{\prime}(R)=[1-(1-\alpha) \gamma] r / \alpha>0 \quad$ and $\quad \lim _{R \rightarrow R_{\max } / 2} \operatorname{RHSL}^{\prime}(R)=0 \quad$ and RHSL' $^{\prime}(R)$ is continuous. In analogy to the proof of Proposition 2 we know that $\operatorname{LHSL}^{\prime}(R)>0$ for all $R$ in $\left(0, R_{\max }\right)$. Thus, since by assumption $\lim _{R \rightarrow 0^{+}} \operatorname{LHSL}^{\prime}(R)<$ $\lim _{R \rightarrow 0^{+}} \operatorname{RHSL}^{\prime}(R)$ and $\operatorname{LHSL}^{\prime}\left(R_{\text {max }} / 2\right)>\operatorname{RHSL}^{\prime}\left(R_{\max } / 2\right)$, it follows from continuity 
of $\operatorname{LHSL}^{\prime}(R)$ and $\operatorname{RHSL}^{\prime}(R)$ that

$\operatorname{LHSL}^{\prime}(R)=\left\{\left[1+g^{\prime}(R)\right](1+\beta)+\beta g^{\prime \prime}(R) R\right\} /(1+\beta)>$

$\operatorname{RHSL}^{\prime}(R)=g^{\prime}(R)\left\{\alpha(\alpha+\beta)-2 \alpha(1+\beta) \lambda g(R)+(1+\beta) \lambda^{2} g(R)^{2}\right\} /(1+\beta)[\alpha-\lambda g(R)]^{2}$ which equals $g^{\prime}(R)<d X_{t} / d R_{t}(R)$ for $R \in\left(0, R_{\max } / 2\right]$.

Assume now that the stationary state solution lies in $\left(R_{\max } / 2, R_{\max }\right)$ and therefore $g^{\prime}(R)<0$ and $\operatorname{RHSL}^{\prime}(R)<0$. If again $\operatorname{LHSL}^{\prime}(R) \geq 0$, the claim is proven. If not, the (negative) slope of $\operatorname{RHSL}(R)$ is larger than the (negative) slope of $\operatorname{LHSL}(R)$, i.e. $\operatorname{RHSL}^{\prime}(R)<\operatorname{LHSL}^{\prime}(R)$ since $\operatorname{LHSL}\left(R_{\text {max }}\right)=[1-r(1-\gamma)] R_{\max }>\operatorname{RHSL}\left(R_{\text {max }}\right)=0$. Q.E.D.

\section{A.4 Proof to Proposition 4}

We start again by proving the existence of a stationary state solution were we have to distinguish for the cases identified in Proposition 1. Commencing with the second case, $\lambda<\alpha / r$, it is easy to show that $\operatorname{BR}(R)>0$ for all $R \in\left(0, R_{\max }\right)$ (see Fig. 5). As in the proof to Prop. 3, we can show for this case that $\operatorname{LHSR}(R)=\operatorname{RHSR}(R) \quad$ for $\quad 0<R<R_{\text {max }} \quad$ if $\quad-1-(1-\gamma) r>0$ and moreover $\lim _{R->0^{+}} \operatorname{LHSR}^{\prime}(R)<\lim _{R->0^{+}} \operatorname{RHSR}^{\prime}(R)$ and hence a stationary state solution exists.

On the other hand, when $\lambda \geq \alpha / r$ either $\hat{R}_{1}=\hat{R}_{2}=0$ or only the pole $\hat{R}_{2}>0$ exists. For $R \in\left(0, \hat{R}_{2}\right), \mathrm{BR}(R)<0$ since $\mathrm{BR}^{\prime}(R)>0$. Thus, $\operatorname{LHSR}(R)$ needs to intersect $\operatorname{RHSR}(R)$ to the right of the pole, i.e. $R \in\left(\hat{R}_{2}, R_{\text {max }}\right)$ where $\operatorname{BR}(R)>0$ (see Fig. 6). Hence, $\lim _{\mathrm{R} \rightarrow \hat{\mathrm{R}}_{2}} \operatorname{RHSR}(R)=+\infty$ while $\operatorname{LHSR}\left(\hat{R}_{2}\right)<\infty$. On the other hand, $\operatorname{RHSR}\left(R_{\text {max }}\right)=0$ while $\operatorname{LHSR}\left(R_{\text {max }}\right)>0$. As a consequence of the continuity of both $\operatorname{LHSR}(R)$ and $\operatorname{RHSR}(R)$ for $R \in\left(\hat{R}_{2}, R_{\max }\right), \operatorname{LHSR}(R)=\operatorname{RHSR}(R)$ for $\hat{R}_{2}<R<R_{\max }$.

The proof of the uniqueness is analogous to the proof to Prop. 3.

In order to prove local asymptotic stability of the stationary state $R \in\left(0, R_{\max }\right)$ we have to show again that $0<d R_{t+1} / d R_{t}<1 \Leftrightarrow 1+g^{\prime}(R)-d X_{t} / d R_{t}>0$ $\wedge g^{\prime}(R)<d X_{t+1} / d X_{t}$ both for $R \in\left(0, R_{\max } / 2\right]$ and for $R \in\left(R_{\max } / 2, R_{\max }\right)$ :

$$
\begin{aligned}
& 1+g^{\prime}(R)-d X_{t} / d R_{t}= \\
& \frac{\beta(1-2 \alpha) R+\lambda R\left[1+\beta\left(1+g^{\prime}(R)\right)\right]-\beta \lambda g(R)(3-2 \alpha)\left[1+g^{\prime}(R)\right]}{\left.\left\{(\alpha+\beta) R+\lambda R\left(1+g^{\prime}(R)\right)\right]+\lambda g(R)\{1-2[1+\beta(2-\alpha)]\}\right\}} \\
& -\frac{\beta g^{\prime \prime}(R) R(\alpha R-\lambda g(R))+\beta g(R)-\alpha R}{\left.\left\{(\alpha+\beta) R+\lambda R\left(1+g^{\prime}(R)\right)\right]+\lambda g(R)\{1-2[1+\beta(2-\alpha)]\}\right\}} .
\end{aligned}
$$


The denominator of (A.4) is larger than zero for all $R \in\left(0, R_{\max }\right)$ because the denominator is minimal at $R=0$ and maximal at $R=R_{\max }$ and is strictly monotonically increasing on the interval $\left(0, R_{\max }\right)$ since the second derivative of the denominator with respect to $R$ equals $\{2[1+2(1-\alpha) \beta] \lambda r\} / R_{\max }>0$. The same holds true with respect to the first bracket of the numerator since the second derivative of the expression in the bracket equals $2(1-2 \alpha) \beta \lambda r / R_{\max }>0$. One can show that $\left[(\beta-\alpha) g(R)-\beta g^{\prime \prime}(R) R(\alpha R-\lambda g(R))\right]$ is minimal at $R=0$ and maximal at $R=R_{\max }$ and that this term is increasing with $R$. Then, both the denominator and the numerator of (A.4) are positive for all $R \in\left(0, R_{\max }\right)$.

To show that $g^{\prime}(R)<d X_{t} / d R_{t}$, we need to distinguish again the range of $R$ on which $g^{\prime}(R) \geq 0$ or $g^{\prime}(R)<0$. Consider first the case in which the stationary state solution lies in $\left(0, R_{\max } / 2\right]$ and hence $g^{\prime}(R) \geq 0$. Moreover, $\operatorname{RHSR}^{\prime}(R)>0$ since $\quad \lim _{R \rightarrow 0^{+}} \operatorname{RHSR}^{\prime}(R)=\{[\alpha+\beta-\lambda \mathrm{r}(1+2 \beta)+\alpha \beta \lambda \mathrm{r}] \mathrm{r}\} /(\alpha-\lambda \mathrm{r})>0 \quad$ and $\lim _{R \rightarrow R_{\max } / 2} \operatorname{RHSR}^{\prime}(R)=-(1-\alpha)^{2} \beta \lambda r^{2} /(2 \alpha-\lambda r)^{2}<0 \quad$ and $\operatorname{RHSR}^{\prime}(R) \quad$ is continuous. Clearly, $\operatorname{LHSR}^{\prime}(R)>0$ for all $R$ in $\left(0, R_{\max }\right)$. Thus, since by assumption $\lim _{R->0^{+}} \operatorname{LHSR}^{\prime}(R)<\lim _{R->0^{+}} \operatorname{RHSR}^{\prime}(R)$ and $\operatorname{LHSR}^{\prime}\left(R_{\max } / 2\right)>\operatorname{RHSR}^{\prime}\left(R_{\max } / 2\right)$, it follows from continuity of $\operatorname{LHSR}^{\prime}(R)$ and $\operatorname{RHSR}^{\prime}(R)$ that

$$
\begin{aligned}
\operatorname{LHSR}^{\prime}(R)= & \frac{\left[1+g^{\prime}(R)\right](1+\beta)+\beta g^{\prime \prime}(R) R}{1+\beta}> \\
\operatorname{RHSR}^{\prime}(R)= & \frac{(\alpha R-\lambda g(R))\left\{(\alpha+\beta) R g^{\prime}(R)+(\alpha+\beta) g(R)-2 \lambda g(R)[1+\beta(2-\alpha)] g^{\prime}(R)\right\}}{[\alpha R-\lambda g(R)]^{2}} \\
& -\frac{\left[\alpha-\lambda g^{\prime}(R)\right]\left\{(\alpha+\beta) \operatorname{Rg}(R)-\lambda g(R)^{2}[1+\beta(2-\alpha)]\right\}}{[\alpha R-\lambda g(R)]^{2}},
\end{aligned}
$$

which equals $g^{\prime}(R)<d X_{t} / d R_{t}$ for $R \in\left(0, R_{\max } / 2\right]$.

If, on the other hand, $R \in\left(R_{\max } / 2, R_{\max }\right), g^{\prime}(R)<0$ and $\operatorname{RHSR}^{\prime}(R)<0$. If $\operatorname{LHSR}^{\prime}(R) \geq 0$, the claim is proven. If not, the (negative) slope of $\operatorname{RHSR}(R)$ is larger than the (negative) slope of $\operatorname{LHSR}(R)$, i.e. $\operatorname{RHSR}^{\prime}(R)<\operatorname{LHSR}^{\prime}(R)$ since $\operatorname{LHSR}\left(R_{\max }\right)>\operatorname{RHSR}\left(R_{\text {max }}\right)=0$. Q.E.D. 


\section{A.5 Proof to Proposition 5}

Setting up the Lagrangian to the optimization problem in section 4

$$
\begin{aligned}
\Lambda=\ln C^{1}+\beta \ln C^{2} & +\mu_{-1}^{C}\left[\ln C_{0}^{2}-\ln \left(C_{0}^{2}\right)^{\circ}\right] \\
& +\phi_{0}^{Y}\left[X^{\alpha}\left(1-h\left(R_{0}, X\right) X\right)^{(1-\alpha)}-C^{1}-C_{0}^{2}\right] \\
& +\phi^{Y}\left[X^{\alpha}(1-h(R, X) X)^{(1-\alpha)}-C^{1}-C^{2}\right] \\
& +\phi^{R}[g(R)-X]+\phi_{0}^{R}\left[R_{0}+g\left(R_{0}\right)-R-X\right]
\end{aligned}
$$

yields the following first order conditions:

$$
\begin{gathered}
\frac{C^{2}}{\beta C^{1}}=1+\frac{\phi_{0}^{Y}}{\phi^{Y}}, \\
\frac{\mu_{-1}^{C}}{C_{0}^{2}}=\phi_{0}^{Y}, \\
\phi_{0}^{Y}\left\{\frac{\alpha X^{\alpha}\left(1-h\left(R_{0}, X\right) X\right)^{(1-\alpha)}}{X}-\frac{(1-\alpha) X^{\alpha}\left(1-h\left(R_{0}, X\right) X\right)^{(1-\alpha)} h\left(R_{0}, X\right)}{\left(1-h\left(R_{0}, X\right) X\right)}\right\} \\
+\phi^{Y}\left\{\frac{\alpha X^{\alpha}(1-h(R, X) X)^{(1-\alpha)}}{X}-\frac{(1-\alpha) X^{\alpha}(1-h(R, X) X)^{(1-\alpha)} h(R, X)}{(1-h(R, X) X)}\right\}=\phi^{R}+\phi_{0}^{R}, \\
\phi^{R} g^{\prime}(R)=\phi_{0}^{R}+\phi^{Y}(1-\alpha) X^{\alpha}[1-h(R, X) X]^{-\alpha} h^{\prime}(R, X) X, \\
\ln C_{0}^{2}=\ln \left(C_{0}^{2}\right)^{\circ}, \\
X^{\alpha}\left(1-h\left(R_{0}, X\right) X\right)^{(1-\alpha)}=C^{1}+C_{0}^{2}, \\
X^{\alpha}\left(1-h\left(R_{0}, X\right) X\right)^{(1-\alpha)}=C^{1}+C^{2}, \\
R_{0}+g\left(R_{0}\right)=R+X, \\
g(R)=X .
\end{gathered}
$$

For the reference case without harvest cost, intergenerational efficiency conditions (A.5c)-( A.5d) simplify to: $\alpha X^{\alpha-1}=\left(\phi^{R}+\phi_{0}^{R}\right) /\left(\phi^{Y}+\phi_{0}^{Y}\right), \phi^{R} g^{\prime}(R)=\phi_{0}^{R}$.

When moreover the utility of the initially old generation is disregarded as constraint for utility maximization of the young generation in the stationary state (= 'Golden Age'), $\mu_{-1}^{C}=0$ and hence $\phi_{0}^{Y}=\phi_{0}^{Y}=0$. Then, the remaining efficiency conditions collapse to:

$$
\begin{aligned}
& C^{2} /\left(\beta C^{1}\right)=1, \\
& \alpha X^{(\alpha-1)}=\phi^{R} / \phi^{Y}, \\
& g^{\prime}(R)=0, \\
& X^{\alpha}=C^{1}+C^{2},
\end{aligned}
$$




$$
g(R)=X .
$$

Assume first that the stationary market equilibrium is such that $g^{\prime}(R)>0$. Set provisionally $q=\left(\phi_{0}^{R}+\phi^{R}\right) /\left(\phi_{0}^{Y}+\phi^{Y}\right)$ and $g^{\prime}(R)=\phi_{0}^{Y} / \phi^{Y}=\phi_{0}^{R} / \phi^{R}$. Then, the market equilibrium conditions evaluated at the stationary state, i.e.

$$
\begin{array}{ll}
C^{2} /\left(\beta C^{1}\right)=1+g^{\prime}(R), & p=q\left[1+g^{\prime}(R)\right], \\
\alpha X^{(\alpha-1)}=q, & w=(1-\alpha) X^{\alpha}, \\
X^{\alpha}=C^{1}+C^{2},, & X^{\alpha}=C^{1}+C_{o}^{2}, \\
X=g(R), & X+R=g\left(R_{0}\right)+R_{0}
\end{array}
$$

imply (A.5a')-(A.5i').

Second, assume that $\mu_{-1}^{C}=0$ and $g^{\prime}(R)=0$ hold in the stationary state market equilibrium. $g^{\prime}(R)=0$ yields the modified stationary state market equilibrium conditions

$$
C^{2} /\left(\beta C^{1}\right)=1, \quad \quad p=q .
$$

But $\mu_{-1}^{C}=0$ implies $\phi_{0}^{Y}=\phi_{0}^{R}=0$. Hence we set $q=\phi^{R} / \phi^{Y}$, and the stationary state market equilibrium conditions, (4'), (7"), (8"), (9'), (10'), imply the Golden Age conditions (A.5a'), (A.5c'), (A.5d'), (A.5g') and (A.5i'). Q.E.D.

A.6 Proof to Proposition 6

If unit harvest costs are constant $(h(R)=\lambda)$, the intergenerational efficiency conditions (A.5c')-(A.5d')change to:

$$
\begin{gathered}
\alpha X^{(\alpha-1)}[1-\lambda X]^{(1-\alpha)}-\lambda(1-\alpha) X^{\alpha}[1-\lambda X]^{-\alpha}=\left(\phi^{R}+\phi_{0}^{R}\right) /\left(\phi^{Y}+\phi_{0}^{Y}\right), \\
\phi^{R} g^{\prime}(R)=\phi_{0}^{R},
\end{gathered}
$$

while the other conditions are similar to the model without harvest cost.

Evaluating again the market equilibrium conditions at the stationary state gives (7') and (4'), $\quad p=(q-w \lambda)\left[1+g^{\prime}(R)\right], \quad q=\alpha X^{(\alpha-1)}[1-\lambda X]^{(1-\alpha)}, \quad w=(1-\alpha) X^{\alpha}$ $[1-\lambda X]^{-\alpha}, \quad X^{\alpha}[1-\lambda X]^{(1-\alpha)}=C^{1}+C^{2}, \quad X^{\alpha}[1-\lambda X]^{(1-\alpha)}=C^{1}+C_{0}^{2}$. Setting provisionally $q=\left(\phi_{0}^{R}+\phi^{R}\right) /\left(\phi_{0}^{Y}+\phi^{Y}\right)+\lambda w$ and again $g^{\prime}(R)=\phi_{0}^{Y} / \phi^{Y}=\phi_{0}^{R} / \phi^{R}$, the stationary state market equilibrium conditions imply the intergenerational efficiency conditions (A.5a)-(A.5b), (A.5c")-(A.5d"), and (A.5e)-(A.5i).

As in the case of no-harvest cost, the stationary market equilibrium is intergenerationally efficient only if $g^{\prime}(R)=\phi_{0}^{Y} / \phi^{Y}>0$, i.e. for $R \in\left(0, R_{\max } / 2\right)$. Acknowledging Prop. 3, $\lambda \geq(4 \alpha) /\left(r R_{\max }\right)$ implies inefficiency of the stationary market equilibrium since $g^{\prime}(R)<0$. However, $\lambda<(4 \alpha) /\left(r R_{\max }\right)$ does not imply 
intergenerational efficiency of the stationary state. The upper bound on $\lambda$ ensuring intergenerational efficiency can be obtained by solving $\operatorname{LHSL}\left(R_{\max } / 2\right)=\operatorname{RHSL}\left(R_{\max } / 2\right)$. The solution is $\lambda^{E} \equiv[8 \alpha-4(1-\gamma) r] /$ $\left\{r[2-(1-\gamma) r] R_{\max }\right\}$ which is definitely smaller than $(4 \alpha) /\left(r R_{\max }\right)$. For all $\lambda \leq \lambda^{E}$, the stationary state market equilibrium is intergenerationally efficient (Golden Age included). Q.E.D.

\section{A.7 Proof to Proposition 7}

To evaluate the intergenerational efficiency of stationary state market equilibria with inversely stock dependent harvest cost, we rewrite the intergenerational efficiency conditions (A.5a), (A.5c), and (A.5d) by assuming that $\left(C_{0}^{2}\right)^{\circ}=C^{2}$ and $R_{0}=R .{ }^{17} \quad$ As a consequence of (A.5g)-(A.5i), $\quad g(R)=X \quad$ and $C^{1}=X^{\alpha}[1-\lambda X / R]^{(1-\alpha)}-C^{2}$. Then, (A.5a) can be written as follows:

$$
\frac{C^{2}}{\beta\left\{\left(g(R)^{\alpha}[1-\lambda g(R) / R]^{(1-\alpha)}-C^{2}\right.\right.}=1+\frac{\phi_{0}^{Y}}{\phi^{Y}} .
$$

The condition for efficient harvest (A.5c) can be rewritten as:

$$
\alpha g(R)^{(\alpha-1)}[1-\lambda g(R) / R]^{(1-\alpha)}-(1-\alpha)(\lambda / R) g(R)^{\alpha}[1-\lambda g(R) / R]^{-\alpha}=\frac{\left(1+\phi_{0}^{R} / \phi^{R}\right) \phi^{R}}{\left(1+\phi_{0}^{Y} / \phi^{Y}\right) \phi^{Y}}
$$

with, from (A.5d),

$$
\phi_{R} / \phi^{Y}=\frac{(1-\alpha) g(R)^{\alpha}[1-\lambda g(R) / R]^{-\alpha} \lambda g(R) /(R)^{2}}{-g^{\prime}(R)+\left(\phi_{0}^{R} / \phi^{R}\right)} .
$$

We start with the stationary market equilibrium conditions

$$
\begin{gathered}
C^{2} /\left(\beta C^{1}\right)=1+g^{\prime}(R)+w \lambda g(R) /\left[R^{2}(q-w \lambda / R],\right. \\
p-w \lambda g(R) / R^{2}=\left[1+g^{\prime}(R)\right](q-w \lambda / R), q=\alpha(g(R))^{(\alpha-1)}[1-\lambda g(R) / R]^{(1-\alpha)}, \\
w=(1-\alpha)(g(R))^{\alpha}[1-\lambda g(R) / R]^{-\alpha} .
\end{gathered}
$$

We set provisionally $\phi_{0}^{Y} / \phi^{Y}=g^{\prime}(R)+\left[\lambda w g(R) / R^{2}\right]\left(\phi_{0}^{Y}+\phi^{Y}\right) /\left(\phi_{0}^{R}+\phi^{R}\right)$, $q-\lambda w / R=\left(\phi_{0}^{R}+\phi^{R}\right) /\left(\phi_{0}^{Y}+\phi^{Y}\right)$ and $\phi_{0}^{R} / \phi^{R}=g^{\prime}(R)+\left[\lambda w g(R) / R^{2}\right]\left(\phi^{Y} / \phi^{R}\right)$.

Using the latter two equations together with the first order market equilibrium conditions for $w$ and $q$ mplies the efficiency conditions (A.5a) and (A.5c).

17 This equality settings we used, although implicitly, already in the former case of constant unit cost. 
In order to obtain $\lambda^{E}$ and $R^{E}$, we assume the Golden Age and thus insert (A.7) into (A.6) under $g^{\prime}(R)=\phi_{0}^{Y} / \phi^{Y}=\phi_{0}^{R} / \phi^{R}=0$, and get after simplifying the resulting equation, $(1-\alpha) g\left(R^{E}\right)^{2} \lambda^{E}=-g^{\prime}\left(R^{E}\right) R^{E}\left[\alpha R^{E}-\lambda^{E} g\left(R^{E}\right)\right]$. Solving this equation for $\lambda^{E}$ and inserting the results into the stationary state equation (13), we get $R^{E}=\left(\alpha R_{\max }\right) /[(1-\gamma) r]$. By reinserting $R^{E} \quad$ into $\lambda^{E}=\left[\alpha g^{\prime}\left(R^{E}\right)\left(R^{E}\right)^{2}\right] /$ $\left\{g\left(R^{E}\right)\left[g^{\prime}\left(R^{E}\right) R^{E}-(1-\alpha) g\left(R^{E}\right)\right]\right\}, \lambda^{E}$ is obtained. Note that for $\phi^{R} / \phi^{Y}>0$ in (9) it is not necessary that $g^{\prime}(R)>0$. Q.E.D. 